\title{
Current Developments and Best Practice in Open and Distance Learning
}

\author{
Armando Rocha Trindade \\ Hermano Carmo \\ José Bidarra
}

\begin{abstract}
Through the many documents regularly emitted by those dedicated to this activity, it is comparatively easy to describe factual developments in the field of open and distance education in different places in the world. However, it is much more difficult to produce judgements of value about their quality. Quality is a subjective rather than an absolute concept and may be examined from different analytical perspectives: consumers' satisfaction level, intrinsic value of scientific and technical content of learning materials, soundness of learning strategies, efficiency of organisation and procedures, adequate use of advanced technologies, reliability of student support mechanisms, etc. These parameters should be put into the context of specific objectives, nature of target populations and availability of different kinds of resources. In a specific geographic, social, economic and cultural situation a given set of solutions might be judged as adequate and deserving the qualification of "good practice", while in a different context it could be considered of rather poor quality. The selection of examples in this article is the sole responsibility of the authors: neither should the chosen cases be considered as clearly better than any other one, nor missing cases be interpreted as lack of appreciation or a negative judgement. Finally, the authors are aware of the risks of interpreting trends and trying to extrapolate them into the near future: readers should use their own judgement in accepting (or forcefully rejecting) these projections.
\end{abstract}

\section{Distance Learning Nowadays}

\section{Definitions}

We do not intend to propose new designations or definitions in the field that is currently and briefly described as open and distance learning (ODL). Nevertheless, we propose to widen the corresponding field of application to include most of the possible contexts of education and training, taking into account their initial and continuing features, consider degree and non-degree programmes, and 
embrace all levels of formal education, from school to advanced higher education. There are many different situations of lifelong education and training (see Fig. 1 below). In order to embrace all these different educational situations we are forced to adopt, for the sake of simplicity, inclusive ("passepartout") designations.

Figure 1: Different types of education and training situations and connections between various types.

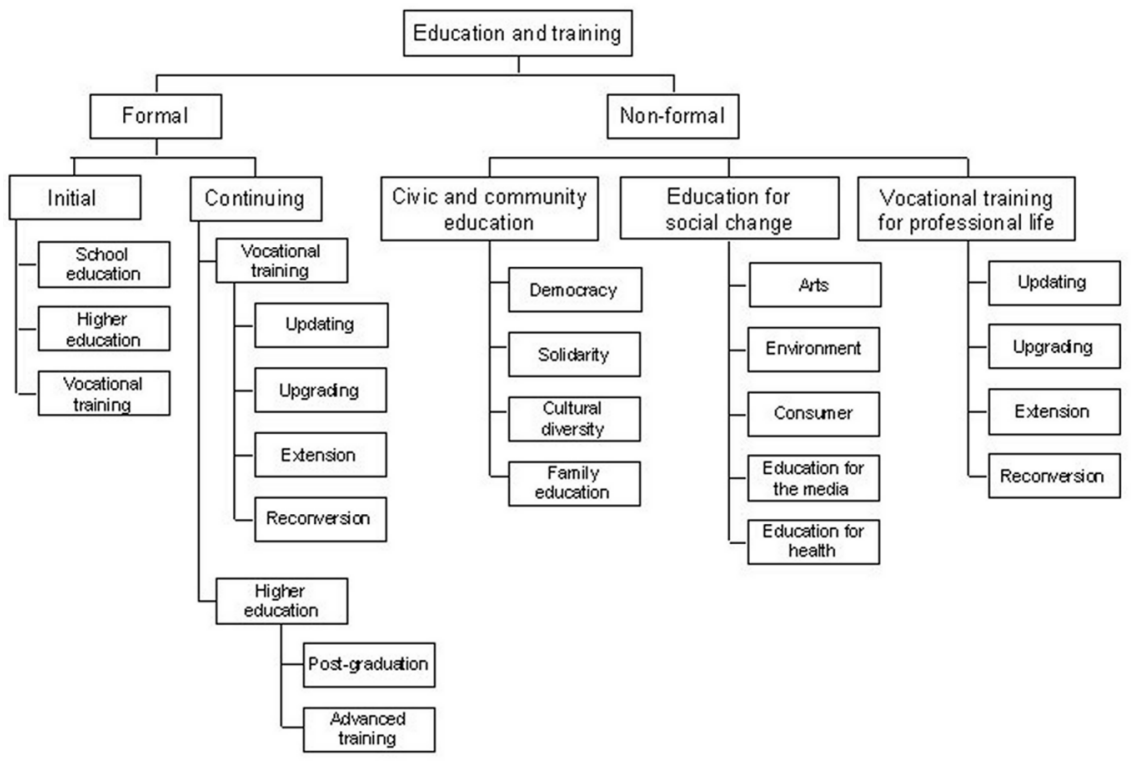

From another point of view, even if we were limited to the context of formal education, it would be possible, according to each precise situation, to use different expressions like distance learning, resource-based learning, distance teaching, distributed learning, flexible learning, remote classroom teaching, and many more. Moreover, looking at the semantics of the word open (frequently used in this field in expressions like open universities and open learning), it may mean either that distance education is the prevailing method used by the teaching system or that there are no prerequisites for access, even for degree programmes.

This situation implies that students and trainees need to have access other than by interpersonal contact to appropriate learning materials: buying books, cassettes or CD-ROMs, receiving broadcasts, using mail or e-mail, accessing the Web. This is, however, not enough, even if these materials have been designed as suitable for self-learning. Distance learning methodology also requires that some kind of support mechanism be available to students, so they can overcome their learning difficulties, get supplementary information, evaluate their own progress and exchange ideas with teachers, tutors and fellow students. (Holmberg, 2000;

International Review of Research in Open and Distance Learning 
Keegan, 1993).

Given these two requisites, teaching and training systems may assume different shapes and mobilise different kinds of technological facilities, according to their objectives, target populations and available resources. We shall call them, from now on, open and distance learning $(O D L)$ systems, whatever the relative proportion of time allocated to self-learning activities and face-to-face ones. The term open and distance learning provides an umbrella designation for all kinds of systems fitting roughly the above requisites (Trindade, 1992).

\section{Systems and Organisations}

Credible ODL systems must have means of establishing an individual link with each member of their universe of users. This means that each student or trainee is identified as a specific person, to whom correspondence is addressed, assignments are sent, marks are attributed and whose questions receive timely answers. In the case of formal programmes, it is the individual student whose learning achievement is assessed and to whom a certificate, diploma or degree may eventually be awarded.

Whatever the format and nature of the ODL system, the above requirements imply that reliable communications and good logistics are available. Both are essential so that the distance between the system and its users does not introduce unacceptable delays between the generic availability of learning materials and their actual handling by the user; between posing a question and getting an answer; between sending an assignment and receiving the corresponding evaluation.

These same requisites become more stringent when the volume of users expands from small to medium, to large, to extra-large. Dealing effectively with tens or even hundreds of thousands of students in absentia requires: following very sound organisational principles and good implementation, systematic monitoring of deviations from established procedures and timings, regular review of users' comments and criticisms as well as careful analysis of final results.

Contrary to conventional, classroom-based teaching, ODL systems are essentially aimed at providing mass education or training; therefore, they have to rely more on capital- and methodology-intensive investments than on manpowerintensive ones. Hence, compared with a ratio of 15 or 20 students to 1 teaching staff in a conventional face-to-face university, for large systems like the so-called Open Universities, the ratio is frequently between 80:1 and 100:1 and in some mega distance education universities, the ratio may actually ascend to 800:1. Obviously, due to the heavier weight of logistics and the presence of instructional designers and media producers in those systems, the ratio between non-teaching and teaching staff is usually higher in distance learning institutions than in con-

International Review of Research in Open and Distance Learning 
ventional ones.

However, the economics of distance education systems (as compared with their conventional counterparts) is clearly favourable in terms of cost-effectiveness; and the more so as the volume of students increases. This is true for both classical open universities (Daniel, 1996) and virtual or networked ones (Ash, 2000; Ortner \& Nickolmann, 1999).

Systems with these characteristics usually rely on flexible organisations and creative management styles to address instructional design and media production issues related to the priorities in development of ODL materials. The relations between instructional design and media production issues and the roles of authors, designers and managers are illustrated in Table 1.

Table 1

\begin{tabular}{|c|c|c|c|}
\hline \multirow{2}{*}{ Main Issues } & \multicolumn{3}{|c|}{ Priorties for the: } \\
\hline & Author & Designer & Hanager \\
\hline $\begin{array}{l}\text { 1. Content is precise and } \\
\text { clear }\end{array}$ & 14.photity & 2 renotery & Fonotity \\
\hline $\begin{array}{l}\text { 2. Communications have } \\
\text { the highest standards for } \\
\text { leaming purposes }\end{array}$ & 27 phonty & 1* photely & 2 prototy \\
\hline $\begin{array}{l}\text { 3. Deadines and costs are } \\
\text { under cortrol }\end{array}$ & II ponotely & I phorty & 14 peorty \\
\hline
\end{tabular}

Relationships between author, designer and manager issues and instructional design/media production issues

\section{Modes of Operation}

The distinction between ODL single-mode and dual-mode organisations is a classical one (Holmberg, 1981). The first designation applies to organisations where distance learning activities are largely dominant as compared with faceto-face ones. This means that, for single-mode systems, students work mostly by themselves outside a campus, their direct contact with the system (e.g., working with tutors, visiting study centres or following summer intensive courses) occupying just a small fraction of the yearly workload. This is the usual organisational pattern of open universities, also known as dedicated distance learning universities.

A different arrangement is followed when conventional universities decide to introduce distance learning methods in some programmes, aimed at extra-mural students, in parallel with their conventional operation. The expression dualmode system reflects the coexistence of distance education and conventional types of operation. This solution has been adopted by an increasing number of 
traditional universities as a means to provide education to students unable to follow courses regularly on campus, thereby expanding the social usefulness and the geographical radius of their influence.

Dual-mode institutions tended to use their distance learning stream mostly for non-degree programmes such as adult and continuing education, while the more prestigious graduate and post-graduate programmes were taught in the conventional, classroom mode. This was the current situation in many North America dual-mode universities some years ago.

In other cases, equivalent formal programmes were taught in the two modes, albeit for different target groups (intra- and extra-mural students), as in the case of the more than 20 French universities associated in the Fédération Interuniversitaire d' Ensignement à Distance (FIED) (http://telesup.univ-mrs.fr) or the University of Southern Queensland (Australia), which considers itself as a model of dual-mode university (http://www.usq.edu.au/).

When the distance learning stream is offered in dual-mode institutions, however, it tends to be assigned a lower priority and to be allocated fewer resources than the conventional stream. Perhaps this is to be expected due to the cultural inertia of older university institutions that tend to frown upon "dangerous innovations" introduced in their usual and comfortable status quo.

Meanwhile, a new model has begun to appear, avoiding the drawbacks of the dual-mode of operation and taking full advantage of the merging of the two teaching methods. We call it the mixed mode, whereby the distance learning and the conventional streams are simultaneously applied, in the same programme, for the same students. From this perspective, one part of the student workload, formerly spent in the classroom and taught by a teacher, is replaced by selflearning activities.

An example of mixed mode is the successful experience of Tele-schools in many regions of the world, some of which have been in operation for more than 40 years. Examples are the Telescola in Portugal, the New Zealand Correspondence School (http://www.correspondence.school.nz) and Tele-ensino in Ceará, Brasil. Designed to provide basic education in remote areas with the sole support of local monitors, they are supported by mail, radio broadcasts, television and, more recently, by more sophisticated communications.

Another example of a mixed mode ODL system from higher education field is the China Central Radio and Television University, one of the largest ODL systems in the world, which delivers course content through satellite transmissions to classrooms. Students work by themselves and interact with teachers working in the central system via wide-band terrestrial cable communications. One of its decentralised structures, the Shanghai Television University, has developed interesting new applications of advanced technologies to improve student's access to learning materials (http://www.shtvu.edu.cn).

International Review of Research in Open and Distance Learning 
The recently created (2000) Universidad Virtual de Andalucia consists of ten universities and polytechnics in this southern region of Spain. Distance education courses are available to students in parallel with current face-to-face teaching activities (http://www.ugr.es).

\section{Convergence of Learning Paradigms}

The classroom mode and the distance learning mode are converging. This is not only due to the success of ODL dual- and mixed-mode experiences but also to progress in information and communication technologies and their permeating all learning environments in most developed countries. Using computers and accessing the Web in schools and universities, taking advantage of quality learning products in CD-ROM, linking institutions through video and computer conferencing all create favourable conditions for increasing students' autonomy and stimulating self-learning. This convergence of technologies obviously means that a shift will be necessary in teachers' profiles and roles. Rather than being the sole owners of knowledge transmitted in the classroom, teachers will become mediators between students and their access to information provided by various sources. This trend has been followed for a number of years through the research activities of the International Council for Open and Distance Education, (http://www.icde.org), the worldwide umbrella organisation for ODL systems (Hall, 1996).

At the Lisbon Summit on Work and Employment in March 2000, heads of state and prime ministers of the European Union agreed to a major joint effort to introduce information and communication technologies (ICT) in all kinds of teaching institutions. This massive project (http://www.portugal.ue-2000.pt/) is intended to improve learning and to prepare future citizens for the needs of the information society.

It is important to note that even dedicated distance learning systems sometimes include classroom instruction, not only to satisfy the need for presential activities in some particular courses but also to reinforce student-system interaction. Giving human faces to otherwise "absent" teachers breaks the isolation of the distance learning student. We have found, by direct experience, that students welcome face-to-face seminars and intensive courses, even if they must sometimes travel from faraway places.

\section{Experimental, Laboratory and Hands-on Experience}

We must accept the fact that in many fields of knowledge, pure distance learning is not suitable for acquiring all necessary attitudes and skills. Some obvious cases in higher education are may be cited:

International Review of Research in Open and Distance Learning 
- health sciences, especially hospital practice

- experimental sciences, which require some time in laboratory environments

- applied psychology, implying direct inter-personal experience

- the final stages of training in law, where oratory and public argumentation skills are of paramount importance

An obvious approach to this difficulty is to separate all theoretical content from the corresponding applications and practice. The former may be efficiently taught in the distance learning mode, and even applications may be presented as case-studies with the full power of sound, image and interactivity as an illustrative introduction to the real, hands-on practice.

Similarly, computer simulation can substitute for real application and practice, as has already happened, successfully, with flight simulators and will happen more and more in the future by progressively maturing the concept of dry lab. However, we are bound to accept the absolute need, in many cases, for face-toface sessions in the appropriate actual working environment.

Many distance teaching systems include face-to-face activities in their programmes, sometimes as intensive courses of an experimental nature. Other institutions avoid offering programmes that require a significant component of experimental practice.

It should be noted, however, that the need to offer opportunities for experimental practice may not be needed in certain continuing (even if advanced) education and training programmes. For a fully qualified and experienced professional the illustration, through appropriate media, of new methods, techniques or equipment may be sufficient to assure the fulfilment of programme objectives.

To further those aims, distance teaching institutions have been very active in establishing partnerships with companies and other organisations. A good example is EuroPACE (http://www.europace.be), a trans-European network of approximately 60 member organisations all over Europe, 45 of which are universities. By using various models, it utilises virtual environments to demonstrate and develop the potential of telematics for vocational training and university teaching. 


\section{Functions of an ODL System}

\section{A General Approach}

Taking as an example of an open university as a fully integrated, dedicated ODL system, we can list the major functions or system capacities for performing the corresponding tasks (Trindade, 1999):

- Specification of programme objectives and target population

- Programme design and curriculum development

- Content authoring

- Instructional design

- Production of learning materials

- Selection and enrolment of students

- Distribution of information and learning materials

- Tutoring and student support

- Assessment and certification

- General and special monitoring

These functions have been listed more or less in the chronological order in which they occur, from the inception of a new programme until the end of its first academic year of operation. Obviously, a number of sub-tasks are embedded in some of these items. For example, conducting a human and material resources feasibility study is part of specifying objectives and the target population, designing the main learning strategies is a sub-task within curriculum development, and selecting media is part of both authoring and production of learning materials. Monitoring is a major aspect of quality assurance, as it provides information and data suitable to have a retroactive effect in improving the performance of all the other functions. Most items in the list do not require further detailing or comment; we shall just deal with the ones deserving a special analysis in the present context.

\section{Distribution Technologies}

A main task for systems using distance learning methodologies (as a major component or just as part of their activities) is to make sure that all learning materials reach students in a timely way. One must take into account that, in

International Review of Research in Open and Distance Learning 
an ODL situation, all relevant information should be accessible, in full, to the student. It is not enough, for instance, to provide students with an extensive bibliographical list, without making sure that all the corresponding references are equally and readily available.

Learning materials may include books and other written documents, radio and television broadcasts, audio and video recordings, interactive courseware and all kinds of documents and information circulating in communication nets (Bates, 1995).

It is currently accepted that all these kinds of documents do not substitute for each other, but rather they complement each other. Books (or the printed page) remain a major tool for studying and learning, as they adapt better to different locations and situations than do documents delivered by electronic media. Experience shows, moreover, that even if texts are originally "published" on the Web, most users print them immediately on paper, rather than studying their content from the screen of a computer.

Moving images and sound are a very useful means of acquiring information of different sorts, often complementary to the information that can be transported by sheets of paper. Broadcasts and permanent magnetic or optical recordings represent two different ways of accessing the information contained therein.

Computers and information technology have made it possible to present directly to the user written content integrated with sound and fixed or moving images. The Internet has added the new dimension of interactivity, allowing users to introduce and to modify data as well as to receive the corresponding feedback.

By adopting a non-sequential (hypertext) architecture in texts and introducing components of sound, fixed images and video clips, we can create new degrees of freedom in the way a document is approached and studied. We can also include a constructionist or "play" component that may increase appeal and facilitate learning (Bidarra \& Guimarães, 1999).

Books and other written documents, cassettes and CD-ROMs can be made available to users either by conventional mail or by distribution in commercial circuits. Sound and video can be broadcast through terrestrial or satellite links, either clear or encrypted, just requiring the users to possess the appropriate receiving equipment.

New communication technologies have created new opportunities for information distribution. All sorts of documents can now be transferred through local, regional or international telephone/computer networks. Mobile phones and portable computers (recently combined into one) have introduced new degrees of spatial freedom.

In addition to supporting materials specially conceived and produced for use in a given distance learning situation, and linking a teaching system and its

International Review of Research in Open and Distance Learning 
individual end-users, the Internet provides access to a huge number of supplementary information sources. However, it is still necessary to ensure that this information is positively related to the subject of study and that sources are credible. Only then can it be judged to be useful and relevant for each previously defined learning objective. This problem has been properly solved by giving students access to the full content of the bibliography recommended for each course, included in an online library. The Open University of Hong Kong (http://www.lib.ouhk.edu.hk) has just implemented such a virtual library, containing more than a half-million books and articles, duly authorised by their publishers.

\section{Student Support Mechanisms}

In a conventional learning situation, interpersonal interactions are usually defined as teacher/student, student/teacher and student/student relationships, and depicted in a triangular pattern. In an entirely distance learning mode, direct contacts of this kind are, except on rare occasions, almost always compromised; some virtual substitutes have to be introduced. Students, prone to be affected by unsolved scientific or pedagogic difficulties in their learning process, by discouragement and demoralisation or by doubts that they are following the right path in the process of knowledge acquisition, should not be forced to work in isolation.

Student support mechanisms are designed to overcome these difficulties. By creating opportunities for contact between students and the teaching system, questions can be asked and answered, advice provided and moral support given whenever needed. Mail and telephone have been used as means for these interactions, as well as study centres where students can meet teachers and tutors at mutually arranged times.

E-mail has introduced a new and more efficient dimension in this process. Even if asynchronous in nature, it is much quicker than conventional mail and much less expensive than the use of phone or of having to travel for a face-to-face meeting. However, we must bear in mind that person-to-person communications are timeconsuming, so the need for adequate student support mechanisms affects the required minimum number of assigned teaching staff. In organisational terms this means that the design of the system cannot afford to become teaching staff-intensive by being too generous with "permanent" availability of tutors to contact students on a person-to-person basis.

On the other hand, e-mail is the perfect tool to diffuse collectively generalinterest information to students: administrative documents and data, formative tests, examination results, news and events.

From another point of view, computer mediated communication (CMC) has 
made it possible to assure student-student interaction through discussion and collaborative-learning groups, thus breaking the traditional and awkward isolation of the distance learning student. Online educators have realised that they can generate effective (small) group discussions when they provide learners with specific tasks to accomplish. It is important to consider the quality of resources, scheduling with precise deadlines and consistent online support.

\section{Technological Facilities}

A distance teaching system needs to have the best technological infrastructure it can afford, namely in data processing for academic and administrative management, and internal circulation of information and technologies for producing and publishing learning materials. However, in distributing these materials and assuring good communications with students, some other considerations must be taken into account.

In the case of a system aiming at providing education to the largest possible population of users, there is a risk of using technologies that are not available to the majority of the target population. This would create social and economic discrimination, with the possibility of excluding the less-favoured part of the universe of potential users from the corresponding benefits.

This is the current situation in developing countries, where information and communication technologies are not widely distributed throughout the population. In many cases, even conventional mail is slow and erratic and telephones scarce and unreliable. A way out of this dilemma is to put distance education into a small number of selected resource centres, where a suitable concentration of the necessary technologies can be made locally available to users (Buitendach, 1997).

The situation may improve in the future through the use of mobile and wireless ICT's, thus increasing the technological autonomy of these education and training centres. Nevertheless, we must recognise that, in many parts of the world and even in some remote regions in developed countries, technology is sometimes at odds with social equity. In Angola, a joint project between Portugal's Universidade Aberta (http://univ-ab.pt) and the Cabinda Gulf Oil Company, a Portuguese language course designated Virtual Journeys, had to rely on a mix of traditional communication means supported by digital media such as CD-ROMs, e-mail and hypertext materials on the Web.

\section{Systems with Missing Functions}

To assure feasibility and sustainability of design, planning and implementation, decisions must take into account the social, economic and cultural context as well

International Review of Research in Open and Distance Learning 
as available resources for launching specific ODL systems. Even when available resources prevent the system to display a full set of ODL requirements, the social utility and opportunity to reinforce the local capacity for human resources development can be key factors in the decision-making process.

We can find several examples of systems working with an incomplete set of functions. For instance, a possibly hard decision for an ODL institution is to avoid the costs (both initial and operating ones) of authoring and producing its own learning materials, choosing instead to import them from an external, credible source. The resulting problem of assuring the cultural and social (as well as pedagogic) compatibility of these materials with the local context can be a major one deserving careful consideration.

Making sure that a suitable number of competent tutors are available and that other student support mechanisms are satisfactory is both expensive and sometimes difficult to achieve. A possible solution is to create partnerships with other institutions working at the same level in the face-to-face, conventional mode. In some other cases, mostly due to legal reasons, assessment and certification procedures are assured by other institutions, again as a form of collaborative partnership. Whatever the situation, the principle of creating partnerships and other forms of networking with similar (and not so similar) organisations is a sound one: synergies are created, economies of scale are achieved and resources (both human and material, usually scarce) are optimised.

\section{Curriculum Development}

\section{Curriculum Flexibility}

One common criticism of earlier distance education practices was their supposed behaviourist, programmed-learning approach. Rigid curricula and content, and uniform learning strategies required of students, without consideration for their different cognitive profiles, were clear drawbacks, even when compared to the advantages of having introduced flexibility of time and place.

The situation has evolved positively meanwhile and curriculum flexibility, associated with the credit-point approach, has been introduced as a matter of course in most distance education systems. This applies also to higher education institutions offering degree programmes, although sometimes subject to limitations imposed by national laws and regulations.

We must also take into account that, apart from the fundamentals of most sciences having a moderate to long lifetime, knowledge is evolving quite rapidly and courses need to be updated more and more frequently. Combined with changes in instructional methods and technologies, the rapid evolution of knowledge

International Review of Research in Open and Distance Learning 
has produced forces for innovation in curriculum development, leading to new degrees of flexibility in courses and subjects.

Updating of instruction is more easily taken for granted in vocational training. Nevertheless, the flexibility of objectives and content brings an added value to these ODL programmes, for it improves their accommodation to the special needs and interests of employers and potential end-users, thus increasing their social and market value. Curricular flexibility has become a major issue in these times of globalisation. While trans-national operation of ODL systems has been made possible by quick and comparatively inexpensive worldwide communications, one has to keep in mind that social, cultural and technological contexts vary widely from region to region across the globe. This means that a distance learning programme devised for a specific target population in a given country might be unsuitable for a different cultural setting; its objectives may not fit exactly users' needs in another kind of environment. This is not just a question of linguistic compatibility, for it is comparatively easy to translate all kinds of content from one language into another; rather, a requisite of cultural contextualisation, so that objectives remain relevant and materials are still appealing and adequate, from the point of view of very different set of users.

We can achieve a higher degree of transferability of content and objectives by "slicing" them into their elementary parts. Taking a course on ecology, as an example, we see that geographic and climatic contexts change widely from continent to continent and from latitude to latitude. Separating the corresponding characteristics into a set of nearly homogeneous regions makes it possible to increase the relevance of this course (or parts of it) for different target populations, in various regions of the globe.

The same reasoning applies to vocational training. To increase transferability and accessibility, instead of devising for each subject of qualification, widespectrum, long-duration programmes, subjects can be separated into smallduration, narrow-band learning modules. Combining selected modules makes for an easier fit to different training requirements. We have called this "The Salami Concept", for it evokes the kind of dish that should not be eaten in large bites but rather by cutting it into thin slices, thus becoming much more palatable. Modularization of content and the consistent use of the credit-point system, allowing for capitalisation of successfully acquired credits of qualification, are proper tools for increasing curriculum flexibility (Jones, Pritchard \& Trindade, 1998). This approach seems to be also adequate for all kinds of continuing education and training programmes that will become in the future a major task for ODL systems. 


\section{Flexibility of Learning Strategies}

Learning strategies can be more or less adequate and efficient according to the cognitive profiles of users. Profiles can range from intellectual-minded persons, at ease with theorisation and abstractions, to the pragmatic and applicationdriven students, who prefer to deal with concrete situations. There are also other possible, intermediate profiles to be considered. Some students are naturally more autonomous and creative in their learning activities so they feel at ease with innovative approaches, with alternative options, and even with the challenge of trying to construct knowledge by themselves. Others prefer a solid and sure approach to fixed objectives and clear and straight content (Kolb, 1984).

In most courses, it seems possible to design different learning strategies suitable for these different kinds of users, albeit serving the same objectives and including approximately the same nature of content.

There is obviously a need for fundamental research on these kinds of issues, dealing with metacognitive profiles, with the process of learning itself and with the devising of alternative learning strategies, for the sake of improving the overall efficiency of learning.

\section{Options on Learning Materials and Processes}

In Europe and the United States there has been some divergence of outlooks about the nature of ODL materials. Following the positive influence of the pioneer British Open University (http://www.open.ac.uk), most ODL systems in Europe place a strong emphasis on the conception and production of high quality learning materials, having embedded an instructional design suitable to facilitate autonomous self-learning. This type of learning is, of course, very expensive and even more so when, besides textbooks, audio, video and multimedia, interactive materials are also produced.

Many United States ODL systems have adopted a different approach, closer to the concept of the asynchronous, remote classroom. Lectures in universities, made by eminent teachers and scientists, are recorded and then broadcast to distance learning students. This live instruction is complemented by the same textbooks used by intra-mural students. In a variation of this approach, systematic and intensive use of videoconferencing multiplies the number of remote classroom sites, operating in a bilaterally interactive, synchronous mode. Another approach uses computer conferencing via Internet, linking a teacher to any number of students. However, when the number of remote sites and the number of students involved increases significantly, the capacity for meaningful teacher-student interaction is naturally compromised.

International Review of Research in Open and Distance Learning 
It is interesting to note that both methods seem to yield good enough results, despite their conceptual and practical differences (Bidarra \& Mason, 1998). In the American case, extra-mural students are brought, in psychological terms, closer to the actual on-campus learning environment, as there is not much difference in their way of studying, compared with residential students. In contrast, European ODL students are led to accept, from the very beginning of their activity, that they will belong to a special, different kind of institution. This requires their adjustment to particular rules of the game, namely the need for self-management of time and assignments, as well as autonomy (also meaning a certain degree of isolation) in their learning.

\section{The Internet in ODL Operations}

The extraordinary expansion and accessibility of the Internet and the World Wide Web over the last decade seems to offer ODL operators a very valuable tool to further the educational aims of people in our contemporary world. If we look around we realise that it is about the Internet that profound academic debate now takes place.

The usually asynchronous nature of the medium and its vast reach make it a powerful tool for both students and teachers around the world who are interested in the same field of knowledge. However, the expression Internet-based learning that we have heard frequently in recent times is, from our point of view, a term we should avoid. We believe that all technologies should be considered as mere tools in the service of distance learning, rather than a seemingly essential factor involved in the learning process. Actually, any tool implies much more than just using intensively a given communication facility: it comprises all the human factors and qualified work involved in conceiving appropriate learning materials; devising a sound pedagogical strategy; providing students, individually, with efficient support mechanisms; assessing their progress; and certifying their results.

Tailor-made, on-demand electronic education raises more than pedagogical, technical or logistic issues. It raises the problem of copyright regulations covering electronic documentation on the Web and of reusing the same hypermedia elements in various combinations (in customised courses) offered to different institutions and companies. Just as the introduction of copying machines led to new legislation on copyright, the electronic distribution of information on a global scale will need to be accommodated as well.

In a nutshell, the results of using the Internet in ODL activities will be only as good as the underlying learning methods, objectives, content and the corresponding implementation. Validation of overall system quality depends, in part, on the credibility of the institution responsible for the whole initiative.

International Review of Research in Open and Distance Learning 
Furthermore, because the Internet is a totally open system, there is a clear risk that unscrupulous organisations may appear to be, from the point of view of a naive prospective user, reliable distance teaching organisations. An attractive home page may describe fees, courses, programmes, degrees and certificates to be awarded. Serious-looking scientific content may be presented, as browsed and downloaded from other sources, and a series of assignments proposed to users. In due time, an impressive (even if worthless) diploma may be delivered.

From another point of view, the use of the Internet fits into the technological change necessary to accommodate some developments in ways and methods of learning. According to Reinhardt (1995), in the information economy knowledge is power but traditional teaching tends to be expensive and slow. With the new technologies learning can be more productive. Table 2 illustrates Reinhardt's comparison of the old and the new models of learning to establish a definite change in educational paradigm.

\section{Table 2}

\begin{tabular}{|c|c|c|}
\hline Old Moded & New Model & Technology Implications \\
\hline Clessroom lectures & Indwidual exploraton & $\begin{array}{l}\text { Networked PCs with access } \\
\text { to infomaton }\end{array}$ \\
\hline Passive absorpoion & Apprenticeship & $\begin{array}{l}\text { Requires skils } \\
\text { development and } \\
\text { simuldobons }\end{array}$ \\
\hline Indhidual wook & Team learning & $\begin{array}{l}\text { Benafts from collaborative } \\
\text { bols and e-mal }\end{array}$ \\
\hline Omnisciert leocher & Teacher as gide & $\begin{array}{l}\text { Relies on occess to experts } \\
\text { cver network }\end{array}$ \\
\hline Stable cortert & Fastchanging cortert & $\begin{array}{l}\text { Requires networks and } \\
\text { publshng tods }\end{array}$ \\
\hline Homogensity & Diversty & $\begin{array}{l}\text { Requires a venidy of } \\
\text { occess tocls and methods }\end{array}$ \\
\hline
\end{tabular}

The old and new paradigms of learning

The idea that the new knowledge media can bring about radical changes in pedagogic methods and in the processes of educational communication reflects a decisive paradigm change. This new relationship between technology and pedagogy has led to a break with the tradition of a teaching methodology based on the "recommended" manual, the teacher's role as primary source of knowledge, and the observance of a fixed curriculum. According to this new paradigm, when we speak of knowledge media we are underlining the importance of knowledge in the global equation; we are not talking about "content ...[for the] information superhighway" (Eisenstadt, 1995). This would be the same as saying that

International Review of Research in Open and Distance Learning 
Beethoven wrote musical notes, i.e., content to play at auditoriums. This qualitative change is important for Eisenstadt who defines knowledge as an emergent property that transcends the concepts of space and time traditionally used in the teaching-learning situation. In other words, it transcends the notion that the student has an empty "reservoir" that has to be filled in from the teacher's full reservoir each time a class is scheduled. Thus knowledge can better be defined as a dynamic process driven by each human being in a unique way. The Internet and the Web are the tools most suited to support this new scenario.

\section{The Evolution of Universities}

\section{General Aspects}

Many factors have influenced, in recent times, the situation and evolution of universities. Wherever they are state-supported institutions (which is mainly the case in Europe) governments tend to apply pressure in order to increase their student capacity, while being reluctant to increase their budgets; they ask universities instead to find alternative sources of financing. Public opinion, on the other end, pushes in that same direction, more and more candidates asking year after year for admission to higher education. One way out of this dilemma is to find appropriate measures to increase the productivity of teaching and learning.

In the United States the problem is somewhat different, the university system being more or less able to cope with the demand for higher education, even if its cost may draw severely on families' budgets. There is, however, strong competition among institutions in recruiting new students.

In both cases, for increasing capacity or for winning over the competition, there is a need to change the perspective of universities, from traditionally aiming at serving elite users, to aiming instead at a process of mass production of graduates. The recently recognised need for lifelong education for all members of the active population of a country (at all levels of education and training, as an efficient means to fight unemployment and to progress in careers) will put an additional burden on university life.

The creation of dedicated Open Universities in the 70s and 80s in all regions of the world was one possible answer to this difficulty. The Open University, UK (http://www.open.ac.uk), the Universidad Nacional de Education a Distancia, Spain (http://www.uned.es) and the FernUniversität, Germany (http://www.fernunihagen.de), in Europe; the UNISA, South Africa, (http://www.unisa.ac.za), that was actually founded as soon as 1946; the Télé-Université (http://www.teluq.uquebec.ca/) and the Athabasca University (http://www.athabascau.ca) in Canada; the Universidad Nacional Abierta, Venezuela (http://www.una.edu.ve) and the Uni-

International Review of Research in Open and Distance Learning 
versidad Estatal a Distancia, Costa Rica (http://www.uned.ac.cr) in South America; the Indira Gandhi Open University, India (http:/www.ignou.edu), the Sukhothai Tammathirat Open University, Thailand (http://www.stou.ac.th) and the University of the Air, Japan (http://www.u-air.ac.jp/hp), in Asia are just a few examples of this type of institution (see, for Web addresses of other ODL institutions, the ICDL database: http://www-icdl.open.ac.uk/).

From another perspective, there is no conventional way for face-to-face teaching institutions to cope with these challenges, without sacrificing their standards of quality; they had to find (and have actually found) unconventional methods of dealing with the problem.

Many conventional institutions have decided to introduce ODL streams of activity as dual- or mixed-mode operations. In the latter case, this means reducing classroom hours and assigning the corresponding saved time to distance learning activities. Freeing classroom space simultaneously means increasing the physical capacity of the institution to accept new students.

Single-mode ODL institutions, in most cases, are able to increase their volume of students without a proportional increase in expenses. Properly designed Open Universities should in principle be able to adapt easily to a significant expansion of their student population (Daniel, 1996), thus in fact lowering student per capita operating costs.

\section{Virtual Universities}

Another interesting approach to the problem of increased demand for higher education has recently begun to appear: the so-called "virtual university". This term intends to mean that, contrary to usual expectations, such institutions have no campus (in a physical sense): ODL students live in a virtual environment, despite their possibility to contact each other, as well as their teachers and tutors, in cyberspace. This situation can occur in a single-mode institution or in dual- and mixed-mode ones; or it can encompass, within the same institutional setting, any number of collaborating organisations.

There is no conceptual difference between a virtual university and other kinds of ODL institutions, just an instrumental one. Virtual systems make an intensive use of ICT technologies, such as WebCT or Lotus Learning Space, to distribute selected learning materials, facilitate access to alternative sources of information and data, make possible teacher-student (as well as student-student) interactions, and enable tutoring and assessment of results. ICT technologies are also used for giving lectures, organising seminars and discussing content.

Perhaps the term virtual, as opposed to real, is not a good choice because institutions strive to develop "real" learning situations online. Harasim, Hiltz, Teles and Turoff (1995) and others (Bacsich, 1997; Bates, 1997; Mason, 1998; Tiffin 
\& Rajasingham, 1995) have explored the possibilities of the new technologies for networked learning. Most of the research and field experience generated in the past decade indicates that computer networking, especially computer mediated communication, can support distance learning courses delivered entirely or partially online. This kind of course delivery can enrich and expand traditional educational activities and support and develop new types of educational interaction both on-campus and off-campus.

The Universitat Oberta de Catalunya (UOC) in Spain (http://www.uoc.es/), a single-mode system, is a case of good practice and a paradigmatic example of a virtual university. The UOC structures its educational strategy around the concept of a virtual campus, which is based on the use of computers and communication networks. Thus, users are able to overcome the boundaries of time and space and engage in interactive contact with all members of the university community: students, tutors, professors and administrative staff. In order to ensure that students have access to resources and receive individualised attention, the UOC has established a network of support centres extending throughout Catalonia. These centres are equipped with a media room, videoconferencing facilities, meeting halls and computer rooms and also organise different activities and cultural events.

Many experiments with networked learning systems have been conducted and the term virtual university is often linked with formerly conventional institutions, that have created dual-mode or mixed-mode systems. Typical cases are Simon Fraser University (http://www.sfu.ca/cde/) and the University of British Columbia (http://www.ubc.ca) in Canada, Stanford Online (http://www.online.stanford.edu) in the United States and the University of Southern Queensland (http://www.usqonline.com.au/) in Australia.

This virtual university approach to higher education ODL is obviously suited for co-operation among similar (and compatible) institutions, wherever they may exist. A very promising idea is for institutions to pool together programmes, courses and learning materials to diversify offerings to students or to create composite programmes, on the understanding they will be mutually recognised. We believe that this kind of joint certification, validated by credible institutions, may increase the interest of prospective users and the intrinsic value of the degrees or diplomas awarded. A typical case of such bilateral arrangements is the association between the Carl von Ossietsky University of Oldenburg (Germany) and the University of Maryland in the United States Joint delivery of a number of online degree courses http://www.umuc.edu/mde/ creates an example of transcontinental ODL operation. The consortium of twenty-one research institutions called Universitas 21 is a case study chosen by Bates (2000) as a typical example of partnerships that provide major (global) advantages to distance teaching organisations. Universitas 21 is a loose consortium of institutions from former British Commonwealth countries, including Scotland, England, Australia, New Zealand, Canada, Hong Kong, and Singapore. It also 
includes the University of Michigan in the United States. Their purposes include common use and certification of existing courses developed by the different partners and joint conception and production of common programmes and materials, thus drawing on the complementary strengths of each partner. On another level, this consortium has agreed to offer a master's programme in sustainable resource management (http://www.universitas.edu.au/projects). Each institution will provide at least two courses dealing with the needs for sustainable resource management in Southeast Asian countries. Each institution will ultimately decide which courses to accept into its own programme. Distributed learning technologies are the basis for the implementation of this joint project.

Another case in point is the Western Governors University

(WGU) (http://www.wgu.edu/wgu/index.html), a unique mega-institution that offers degrees and certificates based completely on competencies - the ability to demonstrate skills and knowledge in a series of assessments, rather than required courses. WGU gathered hundreds of the best distance-delivered classes from 44 institutions across the United States and Athabasca University in Canada into an online catalogue. In this way, students can find credit college classes to complete a credit-based degree programme and gain the competencies necessary for a WGU degree or certificate. By bringing all these classes together in one place, WGU makes it easy for students to find and select classes offered by different institutions in the same subject area according to their needs and learning style. Most of these classes are delivered online within a flexible schedule, while others are term-based and delivered in alternate formats

Another recent example is the German Virtuelle Hochschule Bayern (http://www.vhb.org/). Formerly conventional universities and polytechnics of the region of Bavaria are pooled together, for the purpose of delivering a wide set of distance learning programmes.

Finally, we believe that most of the existing associations, consortia and networks of distance education institutions all over the world, if they are not already offering collaborative programmes based on advanced communications, will do so in the near future. Inter-governmental organisations like the Commonwealth of Learning (with headquarters in Canada) (http://www.col.org/col.htm) and the South East Asia Ministers of Education Organisation (SEAMEO) (http://www.seameo.org) are following the same path.

In conclusion, the concept of networked learning, made possible by the intensive use of ICT's, has created a new flexibility in inter-institutional operations and increased higher education's trans-national scope. This is not only useful for students aiming at getting a degree or diploma, but also for those just looking for classes to take for their own enjoyment and enrichment. Others may be making an incursion into a wholly new promising field, from a continuing education perspective. The possibility of enrolling in any number of interesting high-level courses delivered by a set of prestigious universities will be no less appealing. Due to the foreseeable convergence of their principles, methods and instruments 
of operation, we believe, nevertheless, that the concepts of virtual university, distance teaching university and open university will merge, in the long run, into a single one (whatever name it will be known as).

\section{Conclusion}

At present, globalisation has touched many fields of human activity and introduced many different ways of facilitating day-to-day life. Examples include: direct dialling and instant telephone communications between many places on the planet; e-mail correspondence among increasing numbers of people; access to the Internet for information and data, entertainment, getting things done or having problems solved, shopping and conducting business; getting immediate cash in a foreign country through an ATM; and use of credit cards for shopping or payment of services in many different regions of the world. Globalisation also means quicker international travel, explosion of trans-national tourism, higher degree of mobility of people and merchandise, and worldwide diffusion of news, styles and ideas. It will also mean better opportunities for learning.

However, in other manifestations of globalisation such as worldwide free trade, creation of grand-regional political association of states, and trans-national merging of large businesses and companies, there are still many risks and unknown consequences to be considered. Unless new mechanisms of international solidarity are put into existence, there is the possibility that the gap will widen between developed and developing regions of the world. On the other hand, globalisation and the consequent increase in global competition could precipitate a higher degree of instability of markets and a steady decline of security in employment. Such changes may be triggered by the accelerating diffusion of technological and methodological innovation, thus reducing the lifetime of technical and scientific qualifications.

One response to the danger of losing one's job due to the erosion of professional qualifications or to the loss of markets, causing the breakdown of enterprises, is to increase the average level of active population qualifications. This could be accomplished through both enhanced initial education and training and through expansion of continuing education. The latter will involve upgrading, updating, extending or reconverting professional knowledge and skills, in order to keep abreast of market needs, either as an employee or a self-employed person. Higher education should be able to produce, in the long run, enough graduates to assure that they reach roughly one-half of the active population. Continuing education and training should take the shape of genuinely learning, touching not only the whole occupationally active population but also all remaining members of the civil society. Conventional, classroom-based teaching and training institutions cannot possibly meet these huge quantitative requirements. Distance education methods and techniques are the only realistic way of dealing with this explosion

International Review of Research in Open and Distance Learning 
of universal demand.

Mass education at all levels will be a permanent requirement to meet the challenges of the Knowledge Society. To meet this obvious need, it is expected that conventional institutions will adapt to the use of distance learning methods of operation, so as to increase both their productivity and capacity. Existing dedicated single-mode ODL institutions will probably continue to grow and new ones will be created. On the other hand, the creation of associations, consortia and networks among all these kinds of organisations is a reasonable way to create economies of scale and to share resources and development costs with the possible added value of increasing the global quality of the system.

Many classical approaches to ODL methodology have already been proven by many years of successful operation. On the other hand, development of new methods and facilitation of learning through innovative use of ICT's continues to be a prospect of existing ODL systems. It should be taken into account, nevertheless, that all pedagogic experiences have to be thoroughly evaluated before they can be considered as reliable and adequate.

As ODL systems proliferate, quality assurance will become a major issue. Taking into account our proposed definition of ODL, it is acceptable to evaluate separately its different features, as to their intrinsic quality. Learning materials, with respect to both their scientific content and pedagogic strategies; student support mechanisms; communications; organisation and logistics - all are features to measure and appraise. Self-evaluation of institutions through permanent and generalised monitoring are necessary tools for achieving quality assurance.

Another approach to evaluating quality is by means of peer evaluation, a common form of assessment in higher education. However, the universe of peerage should be restricted to those belonging to the ODL community. This is not a defensive approach: the fact that ODL methods are in essence different from classroom teaching makes those not familiar with that methodology poor judges. Moreover, it is a well-known fact that in many cases and in different regions of the world, conventional universities have been strong opponents to the creation of distance teaching universities.

A pragmatic approach to counter the opposition to ODL is to judge quality in terms of consumer satisfaction. The full specification of objectives to be attained in a given programme will provide users with a yardstick to assess, not only their own performances, but also the reliability and adequacy of the teaching system or institution they have chosen. Their subsequent fitness when entering the profession and their potential to succeed in it will reflect, in the medium term, the quality and value of these qualifications.

Thus open and distance learning systems will be evaluated by public opinion in terms of credibility and prestige, or lack of it; natural selection will kill the bad 
ones and will make the remaining flourish. These will then become examples of good practice.

International Review of Research in Open and Distance Learning 


\section{References}

Ash, C. (2000). A new cost analysis model for networked learning. Proceedings of the First Research Workshop, EDEN: Prague.

Bacsich, P. (1997). Re-engineering the campus with Web and related technology for the virtual university. Conference paper. (Retrieved March 10, 1998: http://www.cms.shu.ac.uk/public/events/flish97/bacsich-paper.htm )

Bates, A. W. (1995). Technology, Open Learning and Distance Education. London and New York: Routledge.

Bates, A. W. (1997). Technology, distance education and national development. Proceedings of the 18th ICDE World Conference, May 1997, University Park, PA: Pennsylvania State University.

Bates, A.W. (2000). Managing technological change: Strategies for college and university leaders. San Fransisco: Jossey-Bass.

Bidarra, J. \& Guimarães, N. (1999). A case for learning sites with video bytes: The hyperscapes experience. Proceedings of Online Educa, November 1999, Berlin.

Bidarra, J. \& Mason, R. (1998). The potential of video in open and distance education. Revista Ibero-Americana de Educacion a Distancia (RIED), 1(2).

Buitendach, A. (1997). The practice of ODL to facilitate work-based learning. Proceedings of ICDE-SCOP Meeting, Lisbon.

Carmo, H. (1998). Educação intercultural e ensino a distância: a questão da formação de formadores. In Seminar Erasmus, May 1998, University of Florence.

Daniel, J. (1996). Mega-universities and knowledge media: Technology strategies for higher education. London: Kogan Page.

Eisenstadt, M. (1995). The knowledge media generation. KMI, The Open University. (Retrieved March 10, 1998: http://kmi.open.ac.uk/kmi-misc/kmifeature.html)

Hall, James, (1996) The educational paradigm shift: Implications for ICDE and the distance learning community. Open Praxis, 2, 27-36.

Harasim, L., Hiltz, S.R., Teles, L., \& Turoff, M. (1995). Learning networks: A field guide to teaching and learning online. Cambridge, MA: MIT Press.

Holmberg, Börje (1981). Status and trends of distance education. London/New York: Kogan Page/ Nichols Publishing.

International Review of Research in Open and Distance Learning 
Holmberg, Börje (2000). Status and trends in distance education research. Proceedings of the First Research Workshop, EDEN: Prague.

Jones, D. R., Pritchard, A. L., \& Trindade, A. R. (1998). Credit transfer and internationalisation of distance education. Open Praxis (2), 5-11.

Keegan, D. (Ed.). (1993). Theoretical principles of distance education. London: Routledge.

Kolb, D.A. (1984). Experiential learning: Experience as the source of learning and development. Englewood Cliffs: Prentice Hall.

Mason, R. (1998). Globalising education: trends and applications. London: Routledge.

Ortner, G. E. \& Nickolmann, F. (Eds.). (1999). Socio-economics of virtual universities. Weinheim: Deutcher Studien Verlag.

Reinhardt, A. (1995, March). New ways to learn. Byte. (Retrieved May 24, 2000: http://www.byte.com/art/9503/sec7/art1.htm)

Tiffin, J. \& Rajasingham, L. (1995). In search of the virtual class: Education in an information society. London: Routledge.

Trindade, A. R. (1992). Distance education for Europe: Terms of reference for a european distance education structure. Lisbon: Universidade Aberta.

Trindade, A. R. (1999). Pursuing quality in educational systems. Proceedings of ICDE Conference on Distance Learning and 21st Century Education Development, Beijing: Tsinghua University.

Citation Format

Trindade, Armando Rocha, Carmo, Hermano \& Bidarra, José (2000) Current Developments and Best Practice in Open and Distance Learning. International Review of Research in Open and Distance Learning: 1, 1. http://www.icaap.org/iuicode?149.1.1.5 